\title{
MODERN METHODS OF DIAGNOSIS AND FORECASTING OF PROLIFERATIVE FORMS OF BENIGN BREAST DYSPLASIA
}

\section{Lukavenko I. M.}

\section{INTRODUCTION}

In the practice of a mammologist there are many patients when precancerous pathological changes in the breast are due not so much to the level of blood hormones, as the level of expression of receptors for them. However, information on the localization of these receptors in the breast is insufficiently covered and relates mainly to studies in breast cancer $(\mathrm{BC})^{1,2,3}$.

The relationship between of the proliferation indicators of breast elements and the level of expression of steroid hormone receptors in particular estrogen in precancerous pathology has been insufficiently studied.

Diagnostic studies of the breast today are focused on the detection of focal neoplasms. The frequency of errors in cytological diagnosis in patients with benign breast tumors reaches $7 \%$, and non-informative puncture $18.6 \%$. Therefore, the diagnosis of precancerous changes in the breast in a significant percentage of cases is impossible.

${ }^{1}$ Estrogen receptor alpha (ESR1) gene amplification is frequent in breast cancer / F. Holst, P.R. Stahl, Ch. Ruiz, O. Hellwinkel, Z. Jehan, M. Wendland, A. Lebeau, L. Terracciano, Kh. Al-Kuraya, F. Jänicke, G. Sauter, R. Simon. Nature Genetics. 2007. V. 39. P. 655-660. URL: https://doi.org/10.1038/ng2006.

${ }^{2}$ Estrogen receptor alpha gene polymorphism and endometrial cancer risk - a casecontrol study / S. Wedren, L. Lovmar, K. Humphreys, C. Magnusson, H. Melhus, A.-Ch. Syvänen, A. Kindmark, U. Landegren, M.L. Fermer, F. Stiger, I. Persson, J.A. Baron, E. Weiderpass. BMC Cancer. 2008. V. 8. ID 322. URL: https://doi.org/10.1186/1471-2407-8-322.

${ }^{3}$ Estrogen receptor alpha haplotypes and breast cancer risk in older Caucasian women / J. Wang, R. Higuchi, F. Modugno, Li J., N. Umblas, J. Lee, L.-Y. Lui, E. Ziv, J.A. Tice, S.R. Cummings, B. Rhees. Breast Cancer Research and Treatment. 2007. V. 106. P. 273-280. URL: https://doi.org/10.1007/s10549-007-9497-8.

${ }^{4}$ Moinfar F. Essentials of Diagnostic Breast Pathology. Berlin : Springer, 2007. V. 1. 193 p. URL: https://doi.org/10.1007/978-3-540-45120-4.

5 Molecular Cytogenetic Comparison of Apocrine Hyperplasia and Apocrine Carcinoma of the Breast / Ch. Jones, S. Damiani, D. Wells, R. Chaggar, S.R. Lakhani, V. Eusebi. The American Journal of Pathology. 2001. V. 158. № 1. P. 207-214. URL: https://doi.org/10.1016/S0002-9440(10)63959-4. 
Recently, article has been done to study the influence of genetic factors, namely simple single nucleotide polymorphisms, on the human phenotype. There is information about the influence of single polymorphisms of the estrogen alpha gene (EsR $\alpha)$ on the development of breast proliferation (see, for example ${ }^{6}$ ). But information on the functional influence of individual polymorphisms is limited. Studying the PvuII polymorphism of the EsR $\alpha$ gene in providing clinicians with information on the specifics of estrogenpositive or estrogen-negative status of breast cancer may contribute to the effectiveness of estrogen therapy.

In view of the above, the study of allelic polymorphism, along with clinical and laboratory parameters in individuals with precancerous processes of the breast will provide useful information for diagnosis, prevention and treatment. Issues of diagnosis of precancerous diseases of the breast, which are factors of $\mathrm{BC}$ high risk remain relevant.

Due to the growing incidence of proliferative forms of mastopathy in recent decades and the young age of people suffering from these processes, it remains important to find mechanisms for early diagnosis and the latest criteria for assessing precancerous diseases. However, currently adopted methods for assessing clinical and instrumental indicators and morphological changes are not informative enough. Because they are mostly invasive, this limits their use in general, especially during pregnancy and lactation. In this regard, the search for molecular genetic predictors of precancerous diseases is becoming increasingly important, which determines the relevance of this problem. It can be concluded that the tasks of diagnosing benign breast dysplasia (BBD), which are high risk factors for cancer, remain relevant and require further scientific research.

\section{Prospects for the diagnosis of benign proliferative forms breast dysplasia}

Methods of selecting patients at risk include questionnaires, ultrasound, self-examination, X-ray diagnosis, determination of basal blood hormones and titer of receptor proteins. According to World health organization experts, tests for mass review should be highly informative (up to $80 \%$ ) and with a low percentage of erroneous results. At the same time, they must be technically simple, able to study a large number of people, quickly analyzed, non-traumatic and economically sound.

${ }^{6}$ Endogenous hormones and breast cancer collaborative group. Endogenous sex hormones and breast cancer in postmenopausal women: reanalysis of nine prospective studies / T. Key, P. Appleby, I. Barnes, G. Reeves. Journal of the National Cancer Institute. 2002. V. 94. № 8. P. 606-616. URL: https://doi.org/10.1093/jnci/94.8.606. 
Electrophysiological methods (electroacupuncture diagnostics, Fol's method), iridodiagnostics, measurement of tissue electrical conductivity and others have not been properly used in practical mammology.

The survey allows to select $38 \%$ of women at risk and to reduce on the $62 \%$ number of people in need of additional examination. The most significant factors reflected in the questionnaire are: overweight after 40 years; first childbirth after 30 years; the first pregnancy after 30 years, which ended in abortion; onset of menstruation after 15 years; acute mental trauma or constant chronic stress; previous breast surgery; malignant diseases of any localization at relatives.

Despite the sufficient number of diagnosing breast diseases modern methods, the clinical method of examination, palpation of the breast and lymphatic outflow areas remain in the first place. In addition, the main diagnostic methods include traditional X-ray examination, ultrasound, magnetic resonance imaging (MRI), interventional diagnosis (biopsy).

The X-ray method is basic in the study of the breast. The advantages include highly informative multi-projection of the image, especially in nonpalpable tumors, the possibility of differential diagnosis, assistance for interventional procedures and more. However, the main disadvantage of mammography is the fact that the dense tissue background in $6 \%$ of those surveyed does not rule out X-ray-negative malignancy. This makes it impossible to use mammography in young women for BBD early diagnosis.

Ultrasound due to its informativeness, non-invasiveness, speed of use, the possibility of repeated conduct without harm to the patient is one of the leading places among other research methods. Ultrasound capabilities have expanded thanks to energy Doppler, native and secondary harmonics, threedimensional imaging, angiography, elastography and more. The main advantages of ultrasound include: the ability to examine pregnant women, examination of young women, differential and interventional diagnosis, dynamic monitoring of treatment. The disadvantages of ultrasound include: the subjectivity of the diagnosis, low informativeness in fat involution. However, despite the complex use of modern diagnostic methods, sometimes the diagnosis remains unclear. The technique of duplex and triplex ultrasound increases the specificity of traditional ultrasound from 83 to $93 \%$, the accuracy of complex diagnosis of breast cancer - from 93 to $98 \%$, the formation that is not determined by palpation - from 62 to $75 \%$.

Nuclear magnetic resonance therapy is characterized by high contrast of soft tissues, allows you to obtain images in any projection with high definition. High specificity is achieved by dynamic examination with intravenous contrast. Indications for the use of nuclear magnetic resonance therapy are studies of young women, pregnant and lactating women, 
multifocal breast lesions, gigantomastia. It is not used in implanted electronic systems and ferromagnetic implants ${ }^{7}$.

Interventional diagnostic methods (biopsy) allow first of all to establish the qualitative nature of the lesion. However, this manipulation must be performed under the control of a method that helps to visualize the tumor reliably. Therefore, biopsy is performed in the presence of a focus of at least $5 \mathrm{~mm}$, and when the tumor is not located in the area of the main vessels and with minimization of iatrogenic complications (pneumothorax) ${ }^{8}$.

Methods of studying the content of hormones and their metabolites are based on immunological methods - radioimmunological and enzyme-linked immunosorbent assay or on immunofluorescent variants of detection of "antigen - antibody" complexes, where the role of antigens is played by hormones and their metabolites. In addition, the immunochromato-mass spectrometric method, which was considered a reference for the study of a number of hormones, has recently become widespread. The advantages of this method are high specificity and accuracy, but still it remains quite expensive. In addition, the concentrations of hormones obtained by different methods may vary.

An important direction in the BBD diagnosis is the development of methods based on which we can predict the risk of cancer. The effect of steroids on breast tissue explains the use of IHC methods to study the receptor status in $\mathrm{BBD}$, as it allows to identify the exact location of tissue or cellular components by immunological and histochemical reactions. Thus the immunological analysis of fabric and biopsy material is carried out in the conditions of preservation of tissue morphology (see, for example ${ }^{9}$ ).

Undoubted role of the immunohistochemical method in the determination of steroid hormone receptors for the possible appointment of a number of hormonal drugs (tamoxifen). Determination of steroid hormone receptors is appropriate for the choice of treatment tactics and to establish the effectiveness of hormone therapy, as the sensitivity of glandular tissue to

${ }^{7}$ Breast Cancer Screening With Imaging: Recommendations From the Society of Breast Imaging and the ACR on the Use of Mammography, Breast MRI, Breast Ultrasound, and Other Technologies for the Detection of Clinically Occult Breast Cancer / C.H. Lee, D.D. Dershaw, D. Kopans, Ph. Evans, B. Monsees, D. Monticciolo, R.J. Brenner, L. Bassett, W. Berg, S. Feig, E. Hendrick, E. Mendelson, C. D'Orsi, E. Sickles, L.W. Burhenne. Journal of the American College of Radiology. 2010. V. 7. № 1. P. 18-27. URL: https://doi.org/10.1016/j.jacr.2009.09.022.

${ }^{8}$ Pneumothorax. A complication of fine needle aspiration of breast tumors / Z. Kaufman, B. Shpitz, M. Shapiro, A. Dinbar. Acta Cytologica. 1994. V. 38. № 5. P. 737-738.

${ }_{9}$ Progesterone receptors $\mathrm{A}$ and $\mathrm{B}$ and estrogen receptor alpha expression in normal breast tissue and fibroadenomas / G. Branchini, L. Schneider, R. Cericatto, E. Capp, I.S. Brum. Endocrine. 2009. V. 35. № 3. P. 459-466. URL: https://doi.org/10.1007/ s12020-009-9176-0. 
hormones is determined by the preservation and functional activity of receptors that have the ability to "receive hormonal signal" and transmit it to the nucleus ${ }^{10}$.

Immunohistochemical method allows you to more accurately assess the risk of possible malignancy of tumors. In identifying the risks of malignant transformation of the breast, the authors proved that the study of receptor status allows to establish the degree of possible transformation, which provides new opportunities for the treatment of patients with BBD various forms (see, for example ${ }^{11}$ ).

The rationale for the introduction of genetic markers in modern medicine is the concept of the pathogenesis of malignant degeneration, which in breast cancer distinguishes a number of successive stages, differing in the properties of the epithelial cells of the ducts and alveoli. The stages of the process of carcinogenesis can be presented in the form of the following series: dysregulation $\rightarrow$ I, II, III centuries hyperplasia $\rightarrow$ neoplasia. The implementation of each stage of transformation requires certain molecular transformations. The whole process requires three to seven independent random changes associated with genetic or epigenetic changes in the function of a number of key proteins - cell cycle regulators ${ }^{12}$.

The role of mutations in the BRCA1 and BRCA2 genes in the development of breast cancer has been proven. In the case of the BRCA1 mutation, it is estimated as an $80 \%$ probability of developing breast cancer when reaching the age of 70 years. However, mutations in the BRCA1 gene are relatively uncommon in sporadic forms of breast cancer. To date, more than 80 risk factors for breast cancer (BC) have been identified, which can be divided into five classes ${ }^{13,14,15,16}$.

10 Prognostic and predictive factors in breast cancer by immunohistochemical analysis / D.C. Allred, J.M. Harvey, M. Berardo, G.M. Clark. Modern Pathology. 1998. V. 11. № 2. P. 155-168.

${ }_{11}$ Medina D. Biological and molecular characteristics of the premalignant mouse mammary gland. Biochimica et Biophysica Acta (BBA) - Reviews on Cancer. 2002. V. 1603. № 1. P. 1-9. URL: https://doi.org/10.1016/S0304-419X(02)00053-7.

12 Genomic Imprinting: Implications for Human Disease / J.G. Falls, D.J. Pulford, A.A. Wylie, R.L. Jirtle. The American Journal of Pathology. 1999. V. 154. № 3. P. 635-647. URL: https://doi.org/10.1016/S0002-9440(10)65309-6.

13 Gumenyuk O.I., Chernenkov Yu.V. Epidemiology of menstrual disorders and diseases of mammary glands in adolescent girls. Endocrine Journal. 2010. V. 57. № 2. P. 608-609.

${ }^{14}$ Gumenyuk O.I., Chernenkov Yu.V. Epidemiology of reproductive disorders and their risk factors in adolescent girls. Hormone Research. 2010. V. 74. № 3. P. 276-277.

${ }^{15}$ Gumenyuk O.I., Chernenkov Yu.V., Eyberman A.S. Mammary glands dysplasia in adolescent girls Abstracts 12th European congress of paediatric and adolescent gynaecology (Plovdiv, May 25-28, 2011). Plovdiv, Bulgaria, 2011. P. 73-74.

${ }^{16}$ Dumitrescu R., Cotarla G.I. Understanding breast cancer risk - where do we stand in 2005? Journal of Cellular and Molecular Medicine. 2005. V. 9. P. 208-221. URL: https://doi.org/10.1111/j.1582-4934.2005.tb00350.x. 
1. Sexual, age, constitutional: female, age over 60 years, tall.

2. Genetic: blood relatives who had breast cancer; family breast cancer; carriers of mutant genes BRCA1 and BRCA2; mutations of other genes p53, ATM, NBS1, LKB1, ER; genetic syndromes; primary-multiple tumors.

3. Reproductive: early menarche (up to 12 years), late menopause (after 54 years), no pregnancies, late first pregnancy (after 30 years), no lactation, abortion.

4. Hormonal and metabolic disorders: hyperestrogenism, hypothyroidism, pituitary hormone metabolism disorders, menstrual disorders, infertility, gynecological diseases, obesity, diabetes, liver disease, hormone replacement therapy, use of combined oral contraceptives for more than 10 years.

5. Environmental factors: living in economically developed countries, high socio-economic status, exposure to ionizing radiation and chemical carcinogens, abuse of alcohol, fats, etc.

In addition, several mathematical models have been proposed that predict the probability of breast cancer - BRCAPRO, the statistical model of Klaus, the model of Gale, Taplin, Rosner ${ }^{17,18}$.

It should be noted that all these models have a high prognostic value in the case of population-based research. To assess individual risk, they are less informative because they do not take into account age, menopause, taking combined oral contraceptives, alcohol use, unilateral or bilateral tumors in close relatives, environmental influences, stress, radiation (Chernobyl), involvement in a particular populations, etc. There is information about several thousand polymorphisms that affect various biochemical processes in the human body. Among the many genetic markers of breast disease is the single-nucleotide PvuII polymorphism of the EsR $\alpha$ gene. Thus, the analysis of literature data shows that among precancerous the breast disease there is a significant molecular heterogeneity.

Modern views on the stage of east cancer draw the scientists attention to the morphological structure of benign tumors. However, the stage of proliferative processes in the breast does not always allow to determine the predisposition of metaplastic tissues to malignant degeneration and, accordingly, to the need for active tactics. However, clinicians do not pay attention to the prevention of breast cancer on the basis of morphological data. Thus, a wide range of structural changes complicates both the diagnosis and treatment of individuals with dyshormonal hyperplasia. Given the above, the development of methods for the

${ }^{17}$ McCormack V.A., Silva I. dos S. Breast density and parenchymal patterns as markers of breast cancer risk: a meta-analysis. Cancer Epidemiology Biomarkers \& Prevention. 2006. V. 15. № 6. P. 1159-1169. URL: https://doi.org/10.1158/10559965.EPI-06-0034.

${ }^{18}$ Tyrer J., Duffy S.W., Cuzick J. A breast cancer prediction model incorporating familial and personal risk factors. Statistics in Medicine. 2004. V. 23. № 7. P. 1111-1130. URL: https://doi.org/10.1002/sim.1668. 
BBD diagnosis should primarily take into account not only the morphological features of the tissue, but also the presence of estrogen receptors. Modern tactics of treatment of patients with dyshormonal hyperplasia should primarily take into account not only the histological BBD features, but also to analyze the stages of proliferation and the prospects of malignancy, taking into account the EsR $\alpha$ expression.

However, information on the functional effects of individual polymorphisms remains limited and there is a high probability that the universal application of these studies to predict estrogen-sensitive diseases is currently limited. The potential role of the PvuII polymorphism of the EsR $\alpha$ gene in parallel with the determination of the hormonal status of breast tissue in providing clinicians with prognostic information on susceptibility to estrogen-sensitive diseases is growing. Along with the clinical characteristics of the disease, determining the state of expression of EsR is an important characteristic that can help create a scheme of individual comprehensive treatment and justify the feasibility of hormone therapy.

Understanding the genetic basis of the pathological process will provide an opportunity to determine the genetic characteristics of the disease an individual patient (genodiagnostics), on the basis of which it will be possible to determine recommendations for a full range of preventive measures. Undoubtedly, the introduction of such an approach in medicine will expand the arsenal of methods of therapy, and possibly gene therapy. In other words, there is a scientifically sound method, which is likely to determine the risk of breast cancer in any woman, and the implementation of certain specially designed preventive measures to eliminate risks and prevent further metaplasia of breast tissue by hormone therapy or surgery.

\section{Materials and research methods}

\subsection{Information substantiation of the research}

Diagnosis and examination of patients who participated in the study were carried out in accordance with the current orders of the Ministry of Healthcare (Ukraine) № 624 from 03.11.2008 and № 645 from 30.07.2010, in compliance with the main provisions of the Council of Europe Convention on Human Rights and Biomedicine, Helsinki Declaration of the World Medical Association on the ethical principles of scientific medical research with human participation and the Order of the Ministry of Health of Ukraine № 690 from 23.09.2009. All patients gave written consent to participate in the study and genetic analysis. The research was conducted on the basis of the Medical Institute of Sumy State University.

Databases of patients and morphological drugs were formed according to the following scheme: 
- passport part (surname, sample number, age, sex, nationality, education, place of residence);

- complaints (pain, tightness, secretions, mastodynia, duration of the disease);

- genotype by PvuII polymorphism of EsR $\alpha$ gene $(\mathrm{C} / \mathrm{C}, \mathrm{C} / \mathrm{T}, \mathrm{T} / \mathrm{T})$;

- anthropometric indicators (weight, height, eye color, foot size);

- anamnestic data (burdened family history of breast disease, breast injury, previous surgery, hormone intake, abortion, menstrual duration, childbirth and lactation, age and onset of menarche);

- stressors and bad habits;

- laboratory indicators;

- comorbidities;

- characteristics of neoplasms (location, number of tumors, size of the affected area, cytomorphological characteristics, histomorphological characteristics, immunohistochemical studies to determine estrogen receptor expression, BIRADS category for ultrasound and mammography, thickness of the glandular component and fibroglandular layer of the breast).

The peculiarities of the anamnesis, stages of diagnosis, clinical picture of proliferative breast dysplasia, consequences of surgical treatment, morphogenesis of neoplasms and genetic features of patients are thoroughly studied. In accordance with the goals and objectives of the first stage, the analysis of somatic and reproductive health of women who participated in the study, carefully studied the family history of diseases of the reproductive system and breast in particular.

All patients were treated surgically. The criteria for selecting patients for the study were traits that are considered an indication for genetic testing for breast cancer, namely: multiple primary tumors in one organ; multiple primary tumors in different organs; bilateral primary tumors in paired organs; multifocal within one organ; the appearance of a tumor at an early age (up to 21 years); one or more close relatives with the same type of tumors; two relatives or more with the same type of tumor; two relatives and more with tumors of one localization; two or more relatives with tumors belonging to familial cancer; two relatives or more with a rare form of cancer; three relatives and more in two generations with tumors of one localization.

The exclusion criteria were: nonproliferative changes in the breast; no signs of genetic predisposition to breast disease; refusal of the patient to participate in the study. Surgical treatment was performed by standard sectoral resection of the breast, as well as by the author's methods.

Investigated: breast tissue and blood. For histological examination, the material was taken during surgery and placed in a container with formalin. 
Blood from the peripheral vein was taken before or after surgery according to standard methods and stored at $-20^{\circ} \mathrm{C}$.

\subsection{Materials of the clinical database and general clinical research methods}

The work involved modern highly informative research methods using reagents and equipment from leading manufacturers of laboratory and diagnostic equipment.

The main principles during the research were as follows:

- careful study of retrospective data;

- comparison of the clinical course of precancerous diseases of the breast, the results of laboratory, instrumental studies with morphological and IHC features of the tissue of the proliferative form of $\mathrm{BBD}$, as well as the results of molecular genetic studies;

- terms of biochemical, homeostasis and histological examinations, use of instrumental (ultrasound, mammography) and invasive (including biopsy) methods to determine the condition of the breast. In addition to complaints and history, provided a general examination of patients, which assessed the state of the cardiovascular, respiratory, nervous, digestive and urinary systems.

During the external examination of the breast, the size, symmetry, condition of the nipple-areolar complex and regional lymph nodes, the nature of secretions from the gland in their presence were determined. All patients underwent a standard examination: determination of clinical and biochemical parameters of blood, hemostasiogram. Be sure to have a blood test for estradiol. In the presence of secretions from the nipple, their cytological examination was performed.

The presence of estradiol was studied by analyzing a combination of competitive enzyme-linked immunosorbent assay and fluorescent determination of reaction products. The observation covered 66 (78.6\%) people of Sumy and $18(78.6 \%)$ - Sumy region. The average age of the surveyed was $(32.3 \pm 1.1)$ years and was in the range of $16-62$ years, among them - 83 (96.4\%) ethnic ukrainians and 3 (3.6\%) russians. Examinations and treatments were performed in 2012 - 2013. Among the subjects $-82(97.6 \%)$ women with BBD and $2(2.4 \%)$ men who suffered from gynecomastia with nodules. A close history of breast cancer in close relatives had $33(39.3 \%)$ individuals.

The analysis shows that the townspeople predominated. $65.5 \%$ of patients had higher education. To a greater extent $(69 \%)$ they were young people, which is largely due to the selection criteria for the study. Family history in general and reproductive and "oncological" in particular were meticulously studied. 
The peculiarities of the clinical course and concomitant diseases were studied. Conducted instrumental and laboratory studies. Morphological features of the removed tissues, as well as genetic differences of patients were studied. By age, the subjects were divided into three groups: the first group (under 21 years) included 15 (17.8\%) people, the second (22-39 years) - $43(51.2 \%)$, the third (over 40$)$. years) - $26(31.0 \%)$ studied. When analyzing anthropometric data in the surveyed deviations from population norms were not detected: the average body weight was $(59.4 \pm 1.2) \mathrm{kg}$, the average height $(166.6 \pm 0.63) \mathrm{cm}$, and BMI $(21.41 \pm 0,42) \mathrm{kg} / \mathrm{m}^{2}$.

Bad habits were taken into account. Thus, among the surveyed 36 (42.9\%) people smoked and drank alcohol; 48 (57.1\%) of the subjects did not smoke, and alcohol was consumed very rarely. In the somatic anamnesis of patients among diseases of the cardiovascular system was dominated by autonomic and vascular disorders - $43(51.2 \%)$, among diseases of the gastrointestinal tract - chronic gastritis - $6(7.1 \%)$, among diseases of the endocrine system - the presence of goiter in 9 (10.7\%) patients, episodic increase in estradiol in the blood was found in $10(11.9 \%)$ studied.

The duration of the underlying disease (DMZ) averaged $(2.65 \pm 0.20)$ years. The average size of the affected area ofthe breast was $(22.5 \pm 1.23)$ mm. 44 people (53.4\%) were diagnosed with one breast tumor, 34 (40.5\%) were diagnosed with two tumors, and $6(7.1 \%)$ were diagnosed with three breast lesions. Neoplasms in all subjects were removed with subsequent histological and immunohistochemical examination. Thus, $74.6 \%$ of patients with BBD proliferative form were operated on for multifocal breast lesions. Analysis of anatomical and histological data did not reveal congenital defects or abnormalities in the development of the breast. The height of the fibroglandular tissue according to ultrasound was on average (18.82 \pm 0.64$)$ $\mathrm{mm}$, and the height of the glandular component $-(13.46 \pm 0.47) \mathrm{mm}$, respectively. Bilateral lesions were observed in 30 (35.7\%) patients, and unilateral lesions in $54(64.3 \%)$.

Given the influence of hormonal background, in particular estradiol, on the development of BBD special attention was paid to the analysis of obstetric and gynecological history. Thus, in the studied patients menarche occurred on average at $(13.30 \pm 0.18)$ years. The duration of the menstrual cycle was $(27.81 \pm 0.35)$ days. A history of abortions was noted by $28(33.3 \%)$ women. In addition, almost a third of patients - $26(31 \%)$ - have been taking hormonal contraceptives or gynecological medications for the past five years. Another 58 (69.0\%) patients denied the effects of exogenous hormonal drugs on their body.

From the anamnesis and the results of the survey it was found that $43(51.2 \%)$ patients had not previously been observed or treated for any 
diseases of the genitals, and $41(48.8 \%)$ of the subjects had chronic diseases of the uterus and its appendages: adnexitis, menstrual disorders, ovarian cysts. $42(50.0 \%)$ patients never gave birth. The remaining $42(52.0 \%)$ had a history of childbirth and lactation. Lactation over 6 months was twice in $11(13.1 \%)$ patients, once - in $31(36.9 \%)$ according to the number of births. A history of breast injury was recorded in 17 (20.2\%) subjects.

\subsection{Radiation research methods during the establishment of benign breast dysplasia}

Ultrasound examination was performed using an ultrasound diagnostic system "Toshiba" Nemio XG SSA-580A, made in Japan (multifrequency linear sensor with a frequency of 6-12 MHz). Mammography was performed with a Hologic Lorad M-IV with a Kodak Direct View Classic CR digitizer (USA).

Evaluation of the characteristics of ultrasound and radiological picture was determined by the BIRADS scale of the American College of Radiologists, which provides for 5 categories of changes in the breast:

- 0 category means that according to the radiological examination it is impossible to exclude or confirm pathological changes of the breast. In such cases, additional research methods are indicated;

- 1 category - a variant of the age norm, type and structure correspond to the age, constitution and functional condition of the patient;

- 2 category - cysts and lipomas. Patients are recommended to undergo a screening examination according to age;

- 3 category is the first typical fibroadenomas. X-ray changes in it characterize the nodular form of mastopathy and in the presence of calcifications patients are shown a control examination 3 weeks after the initial detection of changes. In the future for stable sizes -1 time in 6 months. This group also includes the edematous form of mastitis, the dynamic supervision of which is carried out in the process of conservative treatment. In case of ineffectiveness of conservative treatment, the detected changes are "transferred" to the next category;

- 4 category - changes resemble atypical cysts, intraductal tumors, lipogranulomas, fibroadenomas with increased intra- and peritumoral blood flow and fibroadenomas, which tend to increase during dynamic surveillance. X-ray changes in the 4th category have grouped microcalcinates with sizes from 50 to 600 microns. The described changes require morphological examination of the material obtained during the puncture biopsy;

- 5 category - obvious signs of breast cancer. Performed biopsy for morphological confirmation of the diagnosis, given the possibility of systemic therapy and / or radical surgical treatment; to determine the 
histological type of the tumor, the degree of its malignancy, immunohistochemical analysis, determination of its receptor status.

\subsection{Methods of morphological research}

For patients with a proliferative form of mastopathy, breast tissue obtained suboperatively at the border of healthy tissue - the affected area was studied. 134 fragments of mammary glands with proliferative changes removed in 84 patients were studied. The following were performed: macroscopic intraoperative evaluation of the resection site of the pathological fragment; histological examination of breast tissue (healthy and pathological fragments) during staining of araphin sections with hematoxylin-eosin and toluidine blue and picofurcin according to Van Gizon. The material was fixed in $10 \%$ neutral formalin on phosphate buffer, treated on a histological tissue apparatus of the pool "Scientific Scientific Instrumental" (Switzerland) and poured into paraffin. The total time of fixing, holding and pouring the material did not exceed 48 hours.

During the histological examination, a qualitative comparative assessment of the types of proliferative changes, their localization and severity was performed. In the course of work 134 new growths of dairy received from 84 operated patients were studied. In $72(53.7 \%)$ cases, samples from one organ were subjected to morphological examination, and in $62(46.3 \%)$ neoplasms removed with bilateral breast lesions were analyzed. The average time of preclinical observation of the subjects was $(2.78 \pm 0.161)$ years. In this case, the average size of the pathological tumor was equal to $(22.29 \pm 1.02) \mathrm{mm}$.

The results of the distribution of morphological samples of BBD by age show: most of the surgical drugs $94(70.2 \%)$ removed for BBD belonged to young patients (up to 40 years); 40 (29.8\%) morphological samples belonged to patients over 40 years of age. A significant number of morphological samples are due to multiple lesions of the breast. Among the studied morphological drugs BBD 69 (51.5\%) samples were obtained from women who did not give birth, and $65(48.5 \%)$ in patients who gave birth and had lactation. The number of histological samples obtained from women with a history of abortion was $44(32.8 \%)$, the remaining $90(67.2 \%)$ - in patients who had no history of abortion.

All histological samples obtained from the foci of BBD had a typical histological structure and differed in the type of proliferative changes. In most histological samples - $65(48.5 \%)$ - fibroepithelial type of proliferation prevailed. The predominance of myoepithelial type of proliferation was observed in $15(11.2 \%)$. Epithelial lobe and epithelial duct proliferation occurred in $25(18.7 \%)$ and $29(21.6 \%)$ drugs, respectively. 
The study was dominated by samples of BBD with proliferative activity of 3-4 degrees and metaplasia in some areas or samples with a tendency to atypical changes in $86(64.2 \%)$ subjects. Neoplasms with unexpressed proliferative activity of grades 1-2 were a minority $-48(35.8 \%)$ studies. The results of cytological examination were divided into categories from $\mathrm{C} 1$ to $\mathrm{C} 2$ :

- $\mathrm{C} 1$ - inadequate sample. Conclusion $\mathrm{C} 1$ can be obtained for several reasons. Sometimes tumors, even during a biopsy by an experienced doctor, fail to obtain a sample sufficient to make a diagnosis. In this case, a repeat fine-needle biopsy may help. However, for example, fibrous scars are characterized by a small amount of cellular material;

- C2 - benign neoplasm. To establish a definitive diagnosis of a benign neoplasm, more than 5 normal groups of cells must be found in the test material. These are ordered layers against the background of smaller scattered cells arranged in pairs;

- C3 - the pathologist had doubts about the type of tumor. The dominant character indicates the benign nature of the tumor, but there are some elements of atypia. Repeated biopsy recommended;

- C4 - potentially malignant neoplasm. This category includes samples in which few abnormal cells have been found to make a diagnosis;

- C5 - malignant neoplasm. A typical pattern of a malignant neoplasm is said if a significant number of large cells are found in the sample, placed in the field of view in a chaotic order. The size and shape of the cells vary greatly. They may be surrounded by altered blood or dead cells. Morphological polymorphism of changes in breast tissue in its benign dysplasia prompted us to study the peculiarities of the hormonal status of the tissue.

\subsection{Molecular genetic and statistical research}

Venous blood in the studied patients was collected under sterile conditions in monovets of $2.7 \mathrm{ml}$ with potassium salt of ethylenediaminetetraacetic acid $(11.7 \mathrm{~mm})$ (Sarstedt, Germany). The method is based on the use of a lysing reagent with guanidinisocyanate, intended for cell lysis, solubilization of cell debris, as well as for denaturation of cell nucleases.

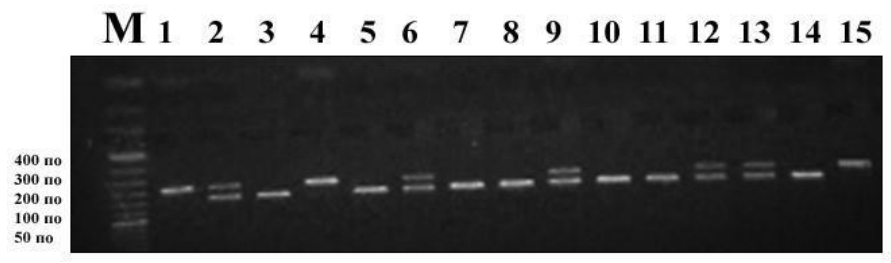

Fig. 1. Fragment of DNA imaging in a transluminator after horizontal agarose gel electrophoresis 
Horizontal electrophoresis $(0.13 \mathrm{~A} ; 200 \mathrm{~V})$ was performed for 35 minutes Visualization of DNA after electrophoresis was performed using a transilluminator ("Biocom", Russia). In Fig. 1 shows the results of restriction analysis of PvuII (1943 T> C) - polymorphism of the EsR $\alpha$ gene, where $\mathrm{M}$ is a molecular weight marker; $\mathrm{PO}$ - pairs of nucleic bases; lanes 1 , 4, 15 correspond to the $\mathrm{C} / \mathrm{C}$ genotype; lanes $2,6,9,12,13$ - C/T genotype; $3,5,7,8,10,11,14-\mathrm{T} / \mathrm{T}$ genotype.

Before analysis, the clinical associations of genotype distribution from the studied PvuII polymorphism were brought into line with Hardy Weinberg law. The idea of genetic balance in populations was first reflected in Hardy-Weinberg's law and forms the basis of the modern concept of the interaction of population-genetic processes. Hardy-Weinberg's law (the law of genetic equilibrium) is the law of population genetics, which establishes the relationship between the frequencies of genes and genotypes in a population with free crossing.

Hardy's law: the population of diploid organisms is so large that random fluctuations in gene frequencies can be ignored; new mutations from the studied gene do not appear in the population; there is no migration of individuals in the population; in the population there is a selection by genotypes studied; in the case of a dichotomous polymorphism, the frequencies of genotypes in the population remain the same from generation to generation and satisfy the Hardy-Weinberg ratio:

$$
p 2+2 p q+q 2=1
$$

where $p$ and $q$ - frequencies of the corresponding alleles.

Under the above conditions, the ratio will remain constant from generation to generation, regardless of changes in population size and values of $\mathrm{p}$ and $\mathrm{q}$. The distribution of alleles and genotype of the PvuII polymorphism of the EsR $\alpha$ gene located on chromosome 6 (6q25.1) was analyzed. All genotypes studied in the study were subject to the Hardy Weinberg relationship.

All the obtained research results were entered into a specially developed thematic table. Statistical processing of the obtained results was performed on a personal computer using the software package "SPSS Statistics 17.0 for Windows". To select statistical research methods, first of all it was determined to which statistical scale (nominal, ordinal, interval) the variables belong. For variables belonging to the interval scale (age, body weight, results of immunohistochemical studies), by constructing histograms with the calculation of the mean value and standard deviation, it was checked whether or not the values are subject to the normal distribution. 
Pearson's $\chi^{2}$ criterion was used to determine the statistical significance of differences in allele and genotype frequencies in groups of patients.

\section{The relationship between the clinical course of benign breast dysplasia depending on the expression of EsR $\alpha$ and the influence of PvuII polymorphism of the EsR $\alpha$ gene}

Using statistical analysis, we studied the relationship of features clinical course of BBD with the main risk factors for the disease. In parallel, the effect of the level of EsR $\alpha$ expression in breast tissue and the allelic distribution of the PvuII polymorphism of the EsR $\alpha$ gene was studied. Given that anthropometric indicators are largely correlated with the development of various pathological conditions, in our study we studied their impact on BBD.

From the table 1 shows that body weight in patients with $\mathrm{BBD}$ proliferative forms is significantly different $(\mathrm{F}=8,050 ; \mathrm{P}=0,001)$, which depends on the genotype of the PvuII polymorphism of the EsR $\alpha$ gene. Thus, in women with genotype $\mathrm{T} / \mathrm{T}$ body weight was equal to $(66.40 \pm 2.97) \mathrm{kg}$, with genotype $\mathrm{T} / \mathrm{C}-(55.94 \pm 1.06) \mathrm{kg}$, with genotype $\mathrm{C} / \mathrm{C}-(58.89 \pm 2.42) \mathrm{kg}$.

According to Duncan's criterion, it was also proved that in patients homozygous for the main allele (T/T) body weight is significantly higher than in heterozygous carriers with $\mathrm{T} / \mathrm{C}$ genotypes and in patients with a minor allele $(\mathrm{C} / \mathrm{C})$.

From the table 1 it can be seen that in patients with proliferative forms of BBD with different genotype by PvuII-polymorphism BMI and foot size revealed a significant difference $(F=5,020 ; P=0,009$ and $F=4,756$; $\mathrm{P}=0,011$, respectively). Using Duncan's criterion, we investigated that the main allele (T/T) homozygotes had significantly higher BMI and foot size than the minor allele $(\mathrm{C} / \mathrm{C})$ and heterozygous carriers with T/C genotypes. .

In addition to mass-growth parameters, the connections between the genetic distribution of the PvuII polymorphism of the EsR $\alpha$ gene with the color of the iris and nicotine dependence were analyzed. Differences in the values of certain indicators and their dependence on variants of genetic polymorphism were not found $\left(\chi^{2}=2.235 ; \mathrm{P}=0.693\right.$ and $\chi^{2}=0.365$; $\mathrm{P}=0.833$, respectively).

Since age is a significant risk factor for diseases of the reproductive system and breast, in particular for breast cancer, in our study it was found that the age of the examined patients with BBD on average was $(32.3 \pm 1.1)$ years. From the Tables 2 and 3 we see that all patients were divided into three age groups.The first group (under 21 years) included 15 (17.8\%) patients, the second group (22-39 years) - 43 (51.2\%), the third (over 40 years $)-26(31.0 \%))$ respectively. Statistical analysis and comparison in each group of receptor status for the expression of EsR $\alpha$ in DDMZ tumors depending on the age of patients showed that EsR $\alpha$-negative occurs in $43.5 \%$ 
of the first group (under 21 years), while EsR $\alpha$-receptor-positive - in 56, $5 \%$. In the second group, receptor-negative samples for EsR $\alpha$ expression were observed in $39.4 \%$, and receptor-positive in $60.6 \%$. In the third group (over 40 years), receptor-negative samples for EsR $\alpha$ occurred in $55.0 \%$, and receptor-positive - in $45.0 \%$.

Table 1

Anthropometric parameters in patients with BBD depending on the variant genotype by Pvull polymorphism of the EsR $\alpha$ gene $(\mathrm{M} \pm \mathrm{m})$

\begin{tabular}{|c|c|c|c|c|c|}
\hline \multirow{2}{*}{ Indicator } & $\mathbf{T} / \mathbf{T}$ & $\mathbf{T} / \mathbf{C}$ & $\mathbf{C} / \mathbf{C}$ & $\mathbf{F}$ & $\mathbf{P}$ \\
\cline { 2 - 5 }$(\mathbf{n = 2 3})$ & $(\mathbf{n = 4 3})$ & $(\mathbf{n = 1 8})$ & & 0.001 \\
\hline Body weight, $\mathrm{kg}$ & $66.40 \pm 2.97$ & $55.94 \pm 1.06$ & $58.89 \pm 2.42$ & 8.050 & 0.001 .69 \\
\hline Height, cm & $168.35 \pm 1,08$ & $165.37 \pm 0.81$ & $167.28 \pm 1.69$ & 2.202 & 0.117 \\
\hline $\begin{array}{c}\text { body mass index, } \\
\mathrm{kg} / \mathrm{m}^{2}\end{array}$ & $23.41 \pm 1.01$ & $20.45 \pm 0.35$ & $21.17 \pm 1.06$ & 5.020 & 0.009 \\
\hline The foot size (eur) & $38.26 \pm 0.29$ & $37.33 \pm 0.151$ & $37.50 \pm 0.31$ & 4.756 & 0.011 \\
\hline $\begin{array}{c}\text { The height of the } \\
\text { glandular component } \\
\text { of the breast (mm) }\end{array}$ & $12.52 \pm 0.65$ & $13.98 \pm 0.76$ & $13.44 \pm 0.70$ & 0.849 & 0.431 \\
\hline $\begin{array}{c}\text { The height of the } \\
\text { fibroglandular } \\
\text { component of the } \\
\text { breast (mm) }\end{array}$ & $19.31 \pm 1.50$ & $18.37 \pm 0.82$ & $19.28 \pm 1.30$ & 0.252 & 0.778 \\
\hline
\end{tabular}

Note: $n$ is the number of people.

Thus, receptor-negative samples in the third group (older than 40 years) occurred 1.3 times more often than in the first group, and 1.4 times more often than in the second group. On the other hand, receptor-negative samples were 1.1 times less frequent in the first group than in the second, and 1.3 times more frequent than in the third group.

During the study of PvuII polymorphism of the EsR $\alpha$ gene among patients - homozygotes by the main allele (T/T) was recorded in $20 \%$, heterozygotes $(\mathrm{T} / \mathrm{C})$ - in $53.3 \%$ of homozygotes of carriers of the minor allele $(\mathrm{C} / \mathrm{C})-26,7 \%$ in (Table 3 ). Thus, the most common variant was T/C-heterozygotes, which was 2.7 times larger than the variant of $\mathrm{T} / \mathrm{T}$ homozygotes, and twice the variant of $\mathrm{C} / \mathrm{C}$ homozygotes. In the second group, the variant of T/T homozygotes was recorded in $23.3 \%$, the variant of $\mathrm{T} / \mathrm{C}$ heterozygotes - in $53.4 \%$, the homozygote $\mathrm{C} / \mathrm{C}-$ in $23.3 \%$. Thus, the $\mathrm{C} / \mathrm{C}$ zygote variant was 2.3 times more frequent than the $\mathrm{T} / \mathrm{T}$ variant and the $\mathrm{C} / \mathrm{C}$ variant with the same frequency. In the third group, the variant of heterozygotes T/C was observed in $46.2 \%$, which was more often than the 
variant of homozygotes $\mathrm{T} / \mathrm{T}$ (38.5\%), 1.2 times and more often than the variant of homozygotes $\mathrm{C} / \mathrm{C}-$ in 3.0 times.

Analysis of the results shows that the receptor status of tumors in BBD did not depend on the age of patients $\left(\chi^{2}=2.525 ; \mathrm{P}=0.283\right)$. In addition, the distribution of allelic variants of the EsR $\alpha$ gene by PvuII polymorphism did not differ statistically in all age groups $\left(\chi^{2}=2.620 ; \mathrm{P}=0.623\right)$. Among the examined patients, no statistical connection between the peculiarities of the receptor status of tumors and PvuII polymorphism depending on age was found.

Table 2

Frequency of EsR $\alpha$ expression in patients of different age groups with BBD

\begin{tabular}{|c|c|c|c|}
\hline \multirow{2}{*}{ EsR $\alpha$ expression } & \multicolumn{3}{|c|}{ Age of patients, $\mathbf{~ ( \% )}$} \\
\cline { 2 - 4 } & up to 21 years & 22-29 years & over 40 years \\
\hline EsR $\alpha-$ & $10(43.5)$ & $28(39.4)$ & $22(55.0)$ \\
\hline EsR $\alpha+$ & $13(56.5)$ & $43(60.6)$ & $18(45.0)$ \\
\hline Total & $23(100)$ & $71(100)$ & $40(100)$ \\
\hline \multicolumn{3}{|c|}{$\chi^{2}=2,525 ; \mathrm{P}=0,283$} \\
\hline
\end{tabular}

Notes: $n$ - number of morphological samples; EsR $\alpha-$ - receptor-negative

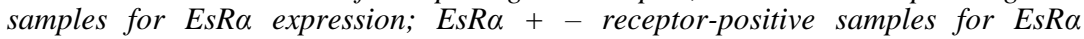
expression.

Table 3

Frequency of allelic variants of the EsR $\alpha$ gene by PvuII polymorphism in patients of different age groups with BBD

\begin{tabular}{|c|c|c|c|}
\hline \multirow{2}{*}{ Genotype } & \multicolumn{3}{|c|}{ Age of patients, $\mathbf{( \% )}$} \\
\cline { 2 - 4 } & up to 21 years & 22-29 years & over 40 years \\
\hline $\mathrm{T} / \mathrm{T}$ & $3(20.0)$ & $10(23.3)$ & $10(38.5)$ \\
\hline $\mathrm{T} / \mathrm{C}$ & $8(53.3)$ & $23(53.4)$ & $12(46.2)$ \\
\hline $\mathrm{C} / \mathrm{C}$ & $4(26.7)$ & $10(23.3)$ & $4(15.3)$ \\
\hline Total & $15(100)$ & $43(100)$ & $26(100)$ \\
\hline \multicolumn{4}{|c|}{$\chi^{2}=2,620 ; \mathrm{P}=0,623$} \\
\hline
\end{tabular}

Note: $n$ is the number of people.

The frequency of the number of removed tumors depending on the genotype of the operated women is given in table. 4 The multiplicity of tumors in the body is an important criterion for a possible genetic predisposition to breast disease. Defeat of two paired organs is an additional reason for the analysis of genetic features of each individual. According to the comparable indicators of the number of removed tumors, depending on the genotype of the PvuII polymorphism of the EsR $\alpha$ gene, it was found that the studied indicators do not depend on the variants of the genetic polymorphism. Thus, the calculation of data by $\chi^{2}$ - Pearson's test showed that the different number of tumors did not depend on the presence of the studied PvuII polymorphism of the $\operatorname{EsR} \alpha$ gene $\left(\chi^{2}=1,512 ; \mathrm{P}=0,824\right)$ (Table 4). 
Depending on the location of BBD tumors, patients were divided into two groups: operated persons with unilateral breast lesions - $54(64.29 \%)$ and operated persons with bilateral lesions - 30 (35.71\%), respectively (Table 4). The table shows that in $\mathrm{C} / \mathrm{C}$ homozygotes the presence of the studied PvuII polymorphism does not differ statistically from the distribution among patients - homozygotes by the main allele (T/T) and does not lead to a special localization of BBD foci. It was found that in the studied group of patients there is no statistical connection between patients with unilateral or bilateral breast lesions and the studied polymorphism $\left(\chi^{2}=1.281 ; \mathrm{P}=0.527\right)$.

Due to the fact that estradiol levels play an important role in ensuring the functioning of the mammary glands, all patients were tested for estradiol levels. An increase in the number of the latter was found in $10(11.9 \%)$ patients. The relationship of different allelic variants by PvuII polymorphism among patients with physiological and elevated blood estradiol levels is shown in table. 5.

The distribution of allelic variants of the EsR $\alpha$ gene studied by the PvuII polymorphism did not differ statistically in patients with physiological blood estradiol levels and in persons with hyperestrogenism $\left(\chi^{2}=0.409\right.$; $\mathrm{P}=0.815)$. Thus, among the patients we operated on, the presence of a pathological genotype $(\mathrm{C} / \mathrm{C})$ of the PvuII polymorphism of the EsR $\alpha$ gene does not lead to the phenomenon of hyperestrogenism.

Table 4

\section{Frequency of allelic variants of the EsR $\alpha$ gene by PvuII polymorphism depending on the number of removed tumors and with unilateral} and bilateral lesions

\begin{tabular}{|c|c|c|c|c|c|}
\hline \multirow{2}{*}{ Genotype } & \multicolumn{3}{|c|}{$\begin{array}{c}\text { The number of removed tumors, } \\
\mathbf{n}(\boldsymbol{\%})\end{array}$} & $\begin{array}{c}\text { Unilateral } \\
\text { lesion,n (\%) }\end{array}$ & $\begin{array}{c}\text { Bilateral lesion, } \\
\mathbf{n}(\boldsymbol{\%})\end{array}$ \\
\cline { 2 - 4 } & $\mathbf{1}$ & $\mathbf{2}$ & $\mathbf{3}$ & $17(31.5)$ & $6(20.0)$ \\
\hline $\mathrm{T} / \mathrm{T}$ & $11(25.0)$ & $11(32.4)$ & $1(16.7)$ & $26(48.1)$ & $17(56.7)$ \\
\hline $\mathrm{T} / \mathrm{C}$ & $24(54.5)$ & $15(44.1)$ & $4(66.6)$ & $11(20.4)$ & $7(23.3)$ \\
\hline $\mathrm{C} / \mathrm{C}$ & $9(20.5)$ & $8(23.5)$ & $1(16.7)$ & $54(100)$ & $30(100)$ \\
\hline Разом & $44(100)$ & $34(100)$ & $6(100)$ & $\chi^{2}=1.281 ; \mathrm{P}=0.527$ \\
\hline & \multicolumn{2}{|c|}{$\chi^{2}=1.512 ; \mathrm{P}=0.824$} & \multicolumn{2}{c}{} \\
\hline
\end{tabular}

Note: $n$ is the number of people.

According to the results presented in Table 6, no association was found between the duration of the menstrual cycle and the onset of menarche in those operated on with proliferative forms of BBD, depending on the variant genotype by the PvuII polymorphism of the EsR $\alpha$ gene. However, it was proved that in patients with different genotypes according to the studied polymorphism, the duration of mensis is different $(\mathrm{F}=3.017 ; \mathrm{P}=0.055)$.

According to Duncan's criterion, we investigated that women homozygotes by minor allele $(\mathrm{C} / \mathrm{C})$ had a longer mensis time than 
heterozygotes $(\mathrm{T} / \mathrm{C})$ and homozygotes by major allele $(\mathrm{T} / \mathrm{T}):(5.67 \pm 0.30)$ days against $(5.47 \pm 0.30)$ and $(4.88 \pm 0.19)$ days, respectively. This proves that the presence of the PvuII polymorphism of the EsR $\alpha$ gene, although it does not change the level of estradiol in the blood, but affects the metabolism of estrogen and, most likely, due to changes in the qualitative or quantitative characteristics of EsR $\alpha$. The clinical reflection of this phenomenon may be the duration of mensis. In our study, we studied the association of nodular goiter as a factor in the development of BBD, with the polymorphism of PvuII of the EsR $\alpha$ gene (Table 7) in the operated patients.

Table 5

Frequency of allelic variants of the EsR $\alpha$ gene by PvuII polymorphism in patients with normal and elevated blood estradiol levels

\begin{tabular}{|c|c|c|}
\hline Genotype & Physiological level, $\mathbf{n}(\%)$ & Elevated level, $\mathbf{n}(\%)$ \\
\hline $\mathrm{T} / \mathrm{T}$ & $21(28.4)$ & $2(20.0)$ \\
\hline $\mathrm{T} / \mathrm{C}$ & $37(50.0)$ & $6(60.0)$ \\
\hline $\mathrm{C} / \mathrm{C}$ & $16(21.6)$ & $2(20.0)$ \\
\hline Total & $74(100)$ & $10(100)$ \\
\hline \multicolumn{2}{|c|}{$\chi^{2}=0.409 ; \mathrm{P}=0.815$} \\
\hline
\end{tabular}

Note: $n$ is the number of people.

Table 6

Gynecological status of operated patients with BBD depending on the variant genotype by Pvull polymorphism of the EsR $\alpha$ gene

\begin{tabular}{|c|c|c|c|c|c|}
\hline Indicator & $\mathbf{T} / \mathbf{T}$ & $\mathbf{T} / \mathbf{C}$ & $\mathbf{C} / \mathbf{C}$ & $\mathbf{F}$ & $\mathbf{P}$ \\
\cline { 2 - 4 } & $(\mathbf{n = 2 3})$ & $(\mathbf{n}=\mathbf{4 3})$ & $(\mathbf{n = 1 8})$ & \\
\hline $\begin{array}{c}\text { Age of menarche onset, } \\
\text { years }\end{array}$ & $13.72 \pm 0.39$ & $13.17 \pm 0.22$ & $13.17 \pm 0.41$ & 0.392 & 0.398 \\
\hline $\begin{array}{c}\text { Cycle duration, } \\
\text { days }\end{array}$ & $27.79 \pm 0.62$ & $27.48 \pm 0.54$ & $28.61 \pm 0.53$ & 0.860 & 0.427 \\
\hline $\begin{array}{c}\text { The duration of mensis, } \\
\text { days }\end{array}$ & $5.47 \pm 0.30$ & $4.88 \pm 0.19$ & $5.67 \pm 0.30$ & 3.017 & 0.055 \\
\hline
\end{tabular}

Note: $n$ is the number of people.

Table 7

The presence of goiter in operated depending on the frequency of allelic variants of the EsR $\alpha$ gene by PvuII polymorphism

\begin{tabular}{|c|c|c|}
\hline Genotype & Available goiter, n (\%) & No goiter, $\mathbf{n}(\%)$ \\
\hline $\mathrm{T} / \mathrm{T}$ & $3(33.3)$ & $20(26.7)$ \\
\hline $\mathrm{T} / \mathrm{C}$ & $5(55.6)$ & $38(50.6)$ \\
\hline $\mathrm{C} / \mathrm{C}$ & $1(11.1)$ & $17(22.7)$ \\
\hline Total & $9(100)$ & $75(100)$ \\
\hline \multicolumn{3}{|c|}{} \\
\hline
\end{tabular}

Note: $n$ is the number of people. 
Nodular goiter with periodic thyroid hormone metabolism was found in $9(10.7 \%)$ women. However, Pearson's calculation revealed no association between goiter formation and the PvuII allelic polymorphism of the EsR $\alpha$ gene. The difference in the distribution of individuals with different allelic variants was insignificant $\left(\chi_{2}=0.669 ; \mathrm{P}=0.716\right)$. This indicates that among the examined patients, the development of nodular goiter did not depend on the presence of PvuII polymorphism of the EsR $\alpha$ gene.

We studied the presence or absence of an association between gynecological diseases among operated patients depending on allelic variants of the PvuII polymorphism of the EsR $\alpha$ gene (Table 8). As we can see, the groups of patients with and without existing gynecological pathology are almost the same: 41 (48.8\%) and 43 (51.2\%). We compared each group of patients by genotypes of the studied polymorphism (Table 8). The $\mathrm{P}$ index, determined by Pearson's $\chi^{2}$ test, was 0.306 . Therefore, the $\mathrm{C} / \mathrm{C}$ genotype of the PvuII polymorphism of the EsRa gene is not associated with the existence of gynecological diseases.

Table 8

Frequency of allelic variants of the EsR $\alpha$ gene by PvuII polymorphism depending on concomitant gynecological diseases

\begin{tabular}{|c|c|c|}
\hline Genotype & $\begin{array}{c}\text { Available gynecological } \\
\text { pathology, n (\%) }\end{array}$ & $\begin{array}{c}\text { There is no gynecological } \\
\text { pathology, n (\%) }\end{array}$ \\
\hline $\mathrm{T} / \mathrm{T}$ & $13(31.7)$ & $10(23.2)$ \\
\hline $\mathrm{T} / \mathrm{C}$ & $22(53.7)$ & $21(48.8)$ \\
\hline $\mathrm{C} / \mathrm{C}$ & $6(14.6)$ & $12(12.0)$ \\
\hline $\mathrm{Pa} 0 \mathrm{M}$ & $41(100)$ & $43(100)$ \\
\hline \multicolumn{2}{|c|}{$\chi^{2}=2.368 ; \mathrm{P}=0.306$} \\
\hline
\end{tabular}

Note: $n$ is the number of people.

\section{CONCLUSIONS}

1. The analysis of clinical and anamnestic indicators does not answer the question of the causes and mechanisms of proliferative changes in BBD. Among the indicators associated with the pathological allele PvuII of the EsR $\alpha$ gene, non-specific indicators (body weight and body mass index).

2. It was found that among the specific symptoms associated with the pathological allele PvuII of the EsR $\alpha$ gene - the duration of mensis and mastodynia. This may be due to progestogen deficiency and estradiol receptor sensitivity.

3. The results of calculations show that BBD begin to form on the background of the preserved menstrual cycle and reproductive function. The crucial role in the development of proliferative foci in BBD is played not by the level of hormones in plasma, but by the state of local estradiol receptors 
in breast tissue. Probably, it is the activity of the receptor that determines the development of the pathological process.

4. It is shown that hormone imbalance promotes morphofunctional adjustment. In some women, this process does not go beyond the physiological norm, in others - in conditions of activation of the receptor apparatus of the breast, pathological conditions are formed. Determining the specifics of the histological structure of the tissue, the features of the receptor apparatus of the cell and genetic predictors can be of primary importance in understanding the causes and mechanisms of proliferation in BBD.

\section{SUMMARY}

The literature data are analyzed and the results of own researches on studying of clinical value of polymorphism of PvuII gene of estradiol alpha receptor in substantiation of indications for surgical treatment of patients with proliferative benign dysplasia of mammary glands are resulted. Specific symptoms associated with the pathological PvuII allele of the EsR $\alpha$ gene have been shown to include mensis duration and mastodynia, due to progestogen deficiency and estradiol receptor sensitivity. The results of calculations show that BBD begin to form on the background of the preserved menstrual cycle and reproductive function. The crucial role in the development of proliferative foci in BBD is played not by the level of hormones in plasma, but by the state of local estradiol receptors in breast tissue. Receptor activity determines the development of the pathological process.

\section{REFERENCES}

1. Estrogen receptor alpha (ESR1) gene amplification is frequent in breast cancer / F. Holst, P.R. Stahl, Ch. Ruiz, O. Hellwinkel, Z. Jehan, M. Wendland, A. Lebeau, L. Terracciano, Kh. Al-Kuraya, F. Jänicke, G. Sauter, R. Simon. Nature Genetics. 2007. V. 39. P. 655-660. URL: https://doi.org/10.1038/ng2006.

2. Estrogen receptor alpha gene polymorphism and endometrial cancer risk - a case-control study / S. Wedren, L. Lovmar, K. Humphreys, C. Magnusson, H. Melhus, A.-Ch. Syvänen, A. Kindmark, U. Landegren, M.L. Fermer, F. Stiger, I. Persson, J.A. Baron, E. Weiderpass. BMC Cancer. 2008. V. 8. ID 322. URL: https://doi.org/10.1186/1471-2407-8-322.

3. Estrogen receptor alpha haplotypes and breast cancer risk in older Caucasian women / J. Wang, R. Higuchi, F. Modugno, Li J., N. Umblas, J. Lee, L.-Y. Lui, E. Ziv, J.A. Tice, S.R. Cummings, B. Rhees. Breast Cancer Research and Treatment. 2007. V. 106. P. 273-280. URL: https://doi.org/10.1007/s10549-007-9497-8.

4. Moinfar F. Essentials of Diagnostic Breast Pathology. Berlin : Springer, 2007. V. 1.193 p. URL: https://doi.org/10.1007/978-3-540-45120-4. 
5. Molecular Cytogenetic Comparison of Apocrine Hyperplasia and Apocrine Carcinoma of the Breast / Ch. Jones, S. Damiani, D. Wells, R. Chaggar, S.R. Lakhani, V. Eusebi. The American Journal of Pathology. 2001. V. 158. № 1. P. 207-214. URL: https://doi.org/10.1016/S00029440(10)63959-4.

6. Endogenous hormones and breast cancer collaborative group. Endogenous sex hormones and breast cancer in postmenopausal women: reanalysis of nine prospective studies / T. Key, P. Appleby, I. Barnes, G. Reeves. Journal of the National Cancer Institute. 2002. V. 94. № 8. P. 606-616. URL: https://doi.org/10.1093/jnci/94.8.606.

7. Breast Cancer Screening With Imaging: Recommendations From the Society of Breast Imaging and the ACR on the Use of Mammography, Breast MRI, Breast Ultrasound, and Other Technologies for the Detection of Clinically Occult Breast Cancer / C.H. Lee, D.D. Dershaw, D. Kopans, Ph. Evans, B. Monsees, D. Monticciolo, R.J. Brenner, L. Bassett, W. Berg, S. Feig, E. Hendrick, E. Mendelson, C. D’Orsi, E. Sickles, L.W. Burhenne. Journal of the American College of Radiology. 2010. V. 7 № 1. P. 18-27. URL: https://doi.org/10.1016/j.jacr.2009.09.022.

8. A complication of fine needle aspiration of breast tumors / Z. Kaufman, B. Shpitz, M. Shapiro, Dinbar A. Pneumothorax.. Acta Cytologica. 1994. V. 38. № 5. P. 737-738.

9. Progesterone receptors $\mathrm{A}$ and $\mathrm{B}$ and estrogen receptor alpha expression in normal breast tissue and fibroadenomas / G. Branchini, L. Schneider, R. Cericatto, E. Capp, I.S. Brum. Endocrine. 2009. V. 35. № 3. P. 459-466. URL: https://doi.org/10.1007/s12020-009-9176-0.

10. Prognostic and predictive factors in breast cancer by immunohistochemical analysis / D.C. Allred, J.M. Harvey, M. Berardo, G.M. Clark. Modern Pathology. 1998. V. 11. № 2. P. 155-168.

11. Medina D. Biological and molecular characteristics of the premalignant mouse mammary gland. Biochimica et Biophysica Acta (BBA) - Reviews on Cancer. 2002. V. 1603. № 1. P. 1-9. URL: https://doi.org/10.1016/S0304-419X(02)00053-7.

12. Genomic Imprinting: Implications for Human Disease / J.G. Falls, D.J. Pulford, A.A. Wylie, R.L. Jirtle. The American Journal of Pathology. 1999. V. 154. № 3. P. 635-647. URL: https://doi.org/10.1016/S00029440(10)65309-6.

13. Gumenyuk O.I., Chernenkov Yu.V. Epidemiology of menstrual disorders and diseases of mammary glands in adolescent girls. Endocrine Journal. 2010. V. 57. № 2. P. 608-609.

14. Gumenyuk O.I., Chernenkov Yu.V. Epidemiology of reproductive disorders and their risk factors in adolescent girls Hormone Research. 2010. V. 74. № 3. P. 276-277. 
15. Gumenyuk O.I., Chernenkov Yu.V., Eyberman A.S. Mammary glands dysplasia in adolescent girls Abstracts 12th European congress of paediatric and adolescent gynaecology. (Plovdiv, May 25-28, 2011). Plovdiv, Bulgaria, 2011. P. 73-74.

16. Dumitrescu R., Cotarla G.I. Understanding breast cancer risk - where do we stand in 2005? Journal of Cellular and Molecular Medicine. 2005. V. 9. P. 208-221. URL: https://doi.org/10.1111/j.1582-4934.2005.tb00350.x.

17. McCormack V.A., Silva I. dos S. Breast density and parenchymal patterns as markers of breast cancer risk: a meta-analysis. Cancer Epidemiology Biomarkers \& Prevention. 2006. V. 15. № 6. P. 1159-1169. URL: https://doi.org/10.1158/1055-9965.EPI-06-0034.

18. Tyrer J., Duffy S.W., Cuzick J. A breast cancer prediction model incorporating familial and personal risk factors. Statistics in Medicine. 2004. V. 23. № 7. P. 1111-1130. URL: https://doi.org/10.1002/sim.1668.

\section{Information about the author: Lukavenko Ivan Mykhailovych, Candidate of Medical Sciences,} Assistant at the Department of Surgery, Traumatology, Orthopedics and Phthisiology Sumy State University 2, Rymskyi-Korsakov str., Sumy, 40007, Ukraine 